\title{
IDENTIFICACIÓN E INCIDENCIA DE LAS CARACTERÍSTICAS LOCALES EN EL PROCESO DE CONSTRUCCIÓN DE POLÍTICAS PÚBLICAS. ANÁLISIS DE LAS POLÍTICAS PÚBLICAS DE CAPACITACIÓN Y FORMACIÓN PROFESIONAL EN ECUADOR
}

\author{
Autora: \\ Irma Jara lñiguez'
}

Artículo basado en la Investigación realizada, previo a la obtención del título de doctorado (PhD), que la autora se encuentra cursando en la Universidad Andina Simón Bolivar. El documento de Tesis se encuentra en evaluación de la Institución.

${ }^{1}$ Universidad Andina Simón Bolivar

Correo electrónico: ijarainiguez@gmail.com

Teléfono (593) 987529777

Quito- Ecuador 


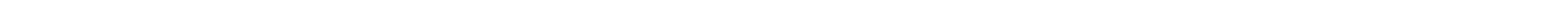




\section{RESUMEN}

Tomando como base las políticas públicas de capacitación y formación profesional que se desarrollaron en Ecuador durante más de tres décadas, la presente investigación identifica las variables que intervienen en la construcción de políticas públicas. Se analiza la incidencia que ejercen variables y constructos como la corrupción, la productividad y la estructura organizacional durante el proceso.

En el estudio se realizó un análisis comparativo diacrónico de las acciones públicas de capacitación y formación profesional y su institucionalidad para el periodo 1978 - 2011, en un total de cuatro fases que se determinaron en consideranción de eventos relevantes que marcaron cambios normativos, económicos, políticos y/o sociales. Empleando una estrategia comparada de similitud y a partir de una evaluación cualitativa, se determinó la incidencia de las variables en la construcción de las políticas públicas.

Se concluye que existe una alta incidencia de la forma de estructura organizacional de las instituciones intervinientes, del grado de productividad laboral y del nivel de corrupción que esté operando o enraizado, en la construcción de políticas públicas; por lo que es necesario considerar estas características locales y las metodologías para abordarlas, para contribuir con la obtención de los resultados y aportar a la comprensión de la complejidad del proceso de construcción de una política pública.

Palabras claves: Capacitación, Corrupción, Estructura organizacional, Políticas públicas, Productividad.

\section{ABSTRACT}

Based on public policies of vocational training that were developed in Ecuador for over three decades, this research identifies the variables involved in the construction of public policies. The incidence that exercises variables and constructs such as corruption, productivity and organizational structure during the process is analyzed.

In the study a diachronic comparative analysis of public actions of vocational training and institutional framework for the period 1978 -2011 was performed in a total of four phases that were determined in consideration of relevant events that marked regulatory, economic, political and / or social changes. Using a comparative strategy of similarity and a qualitative evaluation, the incidence of the variables in the construction of public policies was determined.

We conclude that there is a high incidence of the form of organizational structure of the institutions involved, the level of labor productivity and the level of corruption that is operating or rooted in the construction of public policies; so it is necessary to consider these local features and methodologies to consider them, in order to contribute to obtaining results and contribute to the understanding of the complexity of the construction process of public policy.

Keywords: Corruption, Organizational Structure, Productivity, Public policies, Training. 


\section{INTRODUCCIÓN}

El proceso de construcción de una política pública es complejo e implica la participación de diversos actores y sectores, cada uno con sus características y particularidades, lo que a su vez enriquece la búsqueda de soluciones a un problema público; para comprender dicha complejidad es fundamental considerar las variables que intervienen, de tal forma que se determine la influencia de las características o limitaciones locales y las metodologías para abordarlas, y así poder solucionar el problema público.

Las Políticas de Capacitación implican una intervención o se relacionan con diversas variables como la infraestructura, la arquitectura y la administración estatal y productiva, la educación, la tecnología e innovación, el grado de sofisticación y productividad de los negocios, entre otros y, sus relaciones en las unidades de análisis empresarial, nacional o internacional. No obstante, históricamente en Ecuador, los problemas como el desempleo, subempleo, deficiente competitividad u otros han intentado ser resueltos de forma aislada sin considerar la transversalidad de la capacitación y la formación profesional, ni su interrelación con las distintas variables mencionadas. Con una institucionalidad debil y en constante reforma, en Ecuador existe la percepción en la opinión pública de que las diferentes acciones/ programas implementados en las últimas décadas muestran inconvenientes en su ejecución respecto a su alcance y beneficio; y no se evidencia la solución íntegra del problema público, por lo que, sus resultados no gozan de la entera satisfacción del Estado, ni de la Sociedad.

Se plantea en la investigación que las características productivas, sociales e institucionales influyen por sus interrelaciones en las etapas de formulación, implementación y en la consecución de los objetivos de las políticas públicas, $y$, en específico las relacionadas con la productividad, corrupción y estructura organizacional, y por ello deben ser consideradas en el proceso. Se enfatizó en estas variables porque de acuerdo a los niveles de productividad nacional, las políticas públicas en el ámbito de capacitación requieren enfoques, metodologías y sistemas diferentes ya que las metas, y, los esfuerzos o recursos para conseguirlas serán distintos.

Como se desprende de diversos estudios, la corrupción tiene un impacto negativo directo en el desarrollo de los países, así, según lo indica Echebarría (2004) la corrupción deteriora la credibilidad de las instituciones, la política y los políticos, se merma la legitimidad del Estado, la corrupción puede debilitar los canales legítimos de influencia donde, por medio de la competencia política, los electores pueden tener un impacto en la formulación de políticas, incluso la corrupción puede excluir a ciertos grupos del proceso e incluir a otros, por medio de una relación dependiente entre el ciudadano y los líderes políticos. Teniendo en cuenta que las políticas públicas se estructuran como procesos de recontextualización según enuncia Medellín (2004), su estructuración exige reconocer los límites y posibilidades del proyecto y adecuarlo a las condiciones existentes; se cambian los contextos tanto de gobernantes como gobernados, por lo que, las estructuras organizacionales tienen un rol importante en el proceso de construcción de las políticas públicas.

El estudio de políticas públicas de capacitación y formación profesional en Ecuador se delimitó al periodo de 1978 a 2011, en el que se realizó un análisis comparativo diacrónico, para un total cuatro fases, que se determinaron teniendo en cuenta aspectos relevantes como los cambios constitucionales, de orientación política del gobierno y estos como contexto principal para las acciones públicas propuestas y los cambios institucionales relevantes realizados: Fase 1 de 1978 hasta 1987; Fase 2 de 1988 hasta 1997; Fase 3 de 1998 hasta 2007; Fase 4 de 2008 hasta 2011.

Se analizaron las acciones públicas e instituciones, y las variables involucradas a lo largo del proceso de políticas públicas en el desarrollo de la agenda, formulación, implementación, y evaluación, con énfasis en la agenda y formulación, utilizando la base documental existente, observaciones realizadas y revisión de índices aplicables para cada fase y entre éstas, la mayoría de éstas o en la fase de mayor incidencia.

El problema principal resuelto por la investigación fue identificar las limitaciones que imponen la baja productividad, la corrupción y la estructura organizacional en la construcción de una política pública de capacitación para los trabajadores, y definir una aproximación respecto a la forma en la que se deben considerar estas características locales. En general, se identificó en el período de análisis la incidencia de características relacionadas con: la estructura organizacional de las instituciones de planificación y participantes; la participación y recursos de movimientos sociales, gremios, asociaciones; la identificación política de líderes y autoridades de las instituciones y organizaciones participantes; déficit de presupuesto; duración del gobierno; partido político que gobierna; acontecimientos o desastres naturales; apoyo político al gobierno desde la función legislativa; situación económica del país; grado de productividad; situación económica internacional; percepción de corrupción en el gobierno, en los movimientos sociales, los gremios y asociaciones, en la función legislativa, en las instituciones ejecutoras; resultados de acciones públicas anteriores o vigentes; situación global del país en relación a otros países; posicionamiento de la institucionalidad administrativa en el Estado; fortaleza de los demandantes del servicio; y, tamaño de la oferta del servicio/ alternativas del servicio.

Para la investigación, la amplitud del periodo analizado tornó compleja la selección de referencias analíticas e indicadores y fue una limitante respecto a la disponibilidad y digitalización de la información correspondiente a los distintos periodos en que se constituyeron las fases. 


\section{MÉTODOS Y MATERIALES}

Se emplea la comparación diacrónica para el caso Ecuador para el periodo 1978-2011 centrado en las acciones de capacitación durante el proceso de políticas públicas, en las organizaciones que han tenido un rol trascendental tanto desde el punto de vista de inversión de recursos, así como por la institucionalidad que representan, para las cuatro fases que se separon así: Fase 1, 1978-1987; Fase 2, 1988-1997; Fase 3, 1998-2007; Fase 4, 20082011. Las fases se determinaron teniendo en cuenta los cambios en el contexto y aspectos relevantes referentes a los cambios constitucionales y en la institucionalidad. La selección de acciones e instituciones como unidades de análisis representan un muestreo teórico, y no estadístico, escogiéndose aquellas más representantivas que ofrezcan una mayor oportunidad de aprendizaje y que permitan una generalización empírica.

En la Fase 1: 1978-1987, se inicia un nuevo periodo constitucional, y nuevo periodo democrático; se desarrollan tres gobiernos democráticos (dos de elección y uno de sucesión por ausencia definitiva), tres planes de desarrollo; se verifican tres orientaciones políticas desde el Ejecutivo, la institucionalidad en torno a la capacitación y formación profesional está marcada de forma principal y representativa por la creación del Servicio de Capacitación y Formación profesional, SECAP.

Para la Fase 2: 1988-1997, si bien no se registra cambio de constitución, esta década es políticamente relevante, ya que se evidencian líneas políticas distintas, contando cuatro orientaciones políticas desde el Ejecutivo y varios gobiernos en ejercicio (uno sin terminar periodo y uno de transición), lo que detona un caos de gobernanza y de escándalos de corrupción evidentes para la ciudadanía en general. Se ejecutan dos planes de desarrollo, adicionalmente un plan de acción inmediata y uno de transición. En relación a la institucionalidad de capacitación y formación profesional, se mantiene como entidad principal el SECAP, pero esta evidencia dificultades en el manejo de recursos y para adoptar cambios acordes con el avance tecnológico y de gestión incluso en concordancia con el entorno latinoamericano, y por ende tiene problemas en la consecución de resultados y confianza del sector empresarial. En esta fase se inicia el diálogo social tripartito para la concertación en temas laborales, incluyendo la capacitación y formación profesional de los trabajadores, pero es interrumpido por el Frente Unitario de Trabajadores, debido a desacuerdos en temas relacionados con la seguridad social y remuneraciones.

En la Fase 3: 1998- 2007 se registra una nueva constitución con una nueva orientación política - económica. Esta década es políticamente relevante, ya que se evidencian líneas políticas distintas, contando tres orientaciones políticas desde el Ejecutivo $\mathrm{y}$ varios gobiernos en ejercicio (dos sin terminar periodo $\mathrm{y}$ dos de sucesión), caos de gobernanza que culmina en grandes cambios de institucionalidad, de orientación política y fuerzas políticas predominantes. Se ejecutan tres planes de desarrollo.
En relación a la institucionalidad de capacitación y formación profesional, el Servicio Ecuatoriano de Capacitación y Formación profesional debido a los problemas indicados y registrados en la fase anterior, perdió sus niveles de institucionalidad y representatividad, apareciendo en escena el Consejo Nacional de Capacitación y Formación Profesional CNCF, para el beneficio de los trabajadores del sector privado dependiente y hacia una nueva institucionalidad bajo el enfoque de la constitución vigente.

En la Fase 4: 2008-2011, se aprueba una nueva constitución con distinta orientación política, económica, y de derechos. Esta fase es políticamente relevante, ya que luego de largos periodos de inestabilidad política y de falta de gobernanza, se evidencia en este periodo una permanente y única línea política mayoritaria, el mismo gobierno en ejercicio, aunque se registran intentos para el desequilibrio de las fuerzas y el poder. Se ejecutan y se realiza monitoreo y medición explícito del plan de desarrollo el cual es actualizado en concordancia con la nueva constitución por parte del Gobierno. En relación a la institucionalidad de capacitación y formación profesional, se realizan varios ajustes a las principales instituciones existentes a fin de que sus objetivos y servicios respondan a la nueva orientación constitucional registrándose tres hitos importantes como los cambios en la representatividad dentro del CNCF en el 2009, y posteriormente en el 2010 su supresión como receptor de la contribución de los empleadores del sector privado y, en el 2011 la designación y creación como nuevo ente rector del Comité Interinstitucional de Capacitación y Formación Profesional.

La comparación diacrónica tiene como ventaja que se pueden tomar en cuenta los aspectos históricos, pero su desventaja es la situación desigual de los datos, que puede limitar la comparación principalmente al nivel de datos agregados. Se restringe el análisis a las variables/ constructos clave, ya que, el análisis comparativo puede evitar verse sobrepasado por un número elevado de variables y perder la posibilidad de descubrir relaciones controladas analizando solo las variables clave y omitiendo las que son de importancia marginal (Nohlen, 2006).

Se valoraron a las variables/constructos de productividad y corrupción a través de mediciones de alto, medio y bajo, mediciones que se definieron sobre la base de la información documentada de indicadores sistematizados, identificándose para productividad:

a) para el periodo del 2005-2011, el Índice de Competitividad Global, GCI, elaborado por el Foro Económico Mundial, en el cual está definida la competitividad como el conjunto de instituciones, políticas y factores que determinan el nivel de productividad de un país. El índice incluye un promedio ponderado de los diferentes componentes, donde cada uno mide un aspecto diferente de la competitividad, y estos componentes se agrupan en 12 pilares de competitividad de la economía y se 
definen como instituciones, infraestructura, macroeconomía, salud y educación primaria, educación superior y formación profesional, eficiencia del mercado, eficiencia del mercado laboral, desarrollo del mercado financiero, preparación tecnológica, tamaño de mercado, sofisticación de los negocios, innovación (se anota también que dentro del pilar de eficiencia del mercado se encuentra el indicador de pago y productividad el cual se utiliza para la presente valoración);

b) la Tasa de Crecimiento del Producto Interno Bruto por persona empleada o de la productividad laboral, que son estimaciones realizadas por la Organización Internacional del Trabajo, OIT, $y$, se define como la tasa de crecimiento del producto final, por unidad, del producto inicial (de entrada) insumo de mano de obra, donde el producto terminado se mide como "valor agregado", que es el valor de la producción total menos el valor de los insumos intermedios, tales como materias primas, productos semiacabados, servicios contratados e insumos energéticos; $y$,

c) el Índice de Productividad del Trabajo, con datos de 1990 a 2008, que es la variación anual del producto medio por trabajador y se expresa como un índice en función de un año tomado como referencia (valor 100 para 1990).

En el caso del constructo de corrupción, se identificaron y utilizaron los siguientes: a) el Índice de Percepción de la Corrupción, IPC, de 1980-2011, que se concentra en la corrupción del sector público y define la corrupción como el abuso de un cargo público para el beneficio privado, la escala es de 0 al 10, en donde 10 significa un país totalmente libre de corrupción, bajo las implicaciones de esta metodología. Para este efecto la fuente principal de los datos de este índice es la Organización Transparencia Internacional ${ }^{1}$ y como fuente indirecta CEPAL, a través de su base estadística CEPALSTAT. Además del Índice de Percepción de la Corrupción se han considerado las mediciones de transparencia de las políticas de gobierno, confianza en los políticos y ética de las empresas, que han sido medidas dentro del proceso de construcción del Índice de Competitividad Global, del Foro Económico Mundial.

En aquellos periodos en los que no ha sido posible identificar varios indicadores, se valoró sobre la base de la documentación y fuentes diversas consultadas, esto a fin de dar paso a un análisis académico de las interrelaciones de estas variables/constructos en el proceso de construcción de las políticas públicas.

Respecto a las estructuras organizacionales de las entidades de planificación y participantes (principalmente las ejecutoras), se identificaron y utilizaron datos e información sobre una amplia base documental, documentos e informes públicos de implementación y resultados y/o evaluación de organismos

1 En la actualidad según declaraciones emitidas por el Gobierno de Ecuador, no se reconoce o acepta los resultados emitidos por Transparencia Internacional -organización fundada en 1993en cuestionamiento a las metodologías utilizadas para establecer un índice. No obstante, a efectos de orden académico, y, teniendo en cuenta el análisis de perspectiva histórica que se realizacuyo período incluye épocas en las que Ecuador participaba con dicha organización, así como, ante la inexistencia de otros índices histórica y regionalmente aceptados para éste fenómeno, se incluirán aquí para análisis y discusión dichos resultados de forma referencial, teniendo eso sí en consideración los problemas detectados en la construcción de sus metodologías. nacionales e internacionales como Secretaría Nacional de Planificación y Desarrollo, Consejos Sectoriales, Banco Interamericano de Desarrollo; informes periódicos del Gobierno Central; informes institucionales; registros, indicadores y metas nacionales; indicadores internacionales periódicos; informes históricos; artículos académicos; publicaciones.

Se utilizó el modelo del ciclo de política pública (Jones 1970) presentado por Roth Deubel (2006), como herramienta que permite facilitar el análisis al descomponer el proceso en cuatro etapas o secuencias lógicas: I) la identificación, construcción de problemas y agenda política; II) la formulación de soluciones y decisión; III) la implementación de las decisiones; y, IV) la evaluación de políticas públicas; pero, sin desentenderse de las limitaciones de utilizarlo para operacionalizar y simplificar el abordaje del proceso.

Se incorporaron elementos históricos, políticos, económicos y sociales para comprender los diferentes tipos de evolución de las políticas públicas, así como los rasgos que en distintos contextos presentan los cambios en el rol de las instituciones. Se buscaron explicaciones a los fenómenos político-sociales, partiendo de las proposiciones previas que señalan diferentes variables/ constructos considerados relevantes para estudiar el fenómeno en cuestión, para intentar explicar las diferencias y similitudes a partir del uso de técnicas cualitativas (Bulcourf \& Cardozo, 2008).

Se analizaron las variables involucradas con múltiples fuentes de evidencia y, sobre la base de la integración de los datos obtenidos a través de técnicas de recolección interactivas y no interactivas, el análisis siguió la secuencia temporal de desarrollo de las acciones relacionadas con la capacitación y formación profesional y su organización así como sobre la base del ciclo de política pública; lo que permitió indagar en las características que inciden o afectan a lo largo del proceso de políticas públicas.

El análisis de las políticas públicas es centrado en el estudio del papel de las instituciones planificadores y ejecutoras como el marco en el cual se desarrollan las acciones o políticas públicas. Las instituciones como un factor de orden y construcción de sentido para las acciones realizadas por los actores, las condiciones de producción y de evolución de las instituciones y como éstas a su vez influyen en las dinámicas sociales lo que permite analizar al Estado en interacción.

Se observa el Estado en acción frente a las exigencias nacionales en un contexto político y económico internacional que lo enfrenta a nuevas problemáticas, que influyen sobre su acción. Analizar como las políticas aprobadas reflejan la acción de éste (el poder y sus funciones), describen el comportamiento institucional y por tanto las variaciones de la política se pueden atribuir a la estructura institucional (Roth Deubel, 2006, pp. 15-18).

Si las Políticas públicas corresponden desde un concepto tradicional centrado en el Estado al programa de acción de una 
autoridad pública o el resultado de la actividad de una autoridad investida de poder público y de legitimidad gubernamental (Meny y Thoenig 1992), éstas reflejan la acción del Estado. Por medio de las acciones, las capacidades concretas y los mecanismos de regulación se evidencia al Estado real.

El Estado por medio de las políticas públicas como un conjunto de acciones modifica comportamientos, a su vez, estas decisiones son el resultado de juego de poder entre los diferentes actores (resultando en un reparto de poder). Al observar a los actores revelan el juego de poder y la relación del Estado con el entorno. (Roth Deubel, 2006, p. 20).

Para resolver los problemas públicos los planificadores deben atender la interacción humana y sus características propias en el marco de lo local la cual está influida por reglas, recursos y relaciones de transformación; a las disposiciones institucionales, y a la vinculación entre la interacción humana y las estructuras por medio de ideas, reglas, modos, medios de comunicación y métodos. (Bryson y Crosby en Bozeman; 1998: 436).

Más allá del concepto tradicional demasiado centrado al Estado una política pública corresponde a cursos de acción y flujos de información relacionados con un objetivo público definido en forma democrática y desarrollados por el sector público pero con participación de la comunidad y sector privado (Lahera, 2002, pp. 15-16). Según explica Lahera (2002) las políticas pueden ser utilizadas como unidad básica del análisis institucional, unidad de transacción del sector gubernamental, para fines analíticos, por lo que la organización debería reflejar la naturaleza de las transacciones que realiza.

El neoinstitucionalismo de March y Olson (1984) (2005) lleva a entender la forma en que desarrollan las acciones en las instituciones políticas, los actores políticos cuyos comportamientos se basan en lo correcto, en lo establecido, las prácticas, ritos, es decir prácticas institucionalizadas, identificando los líderes un patrón de comportamiento adecuado (dentro de un conjunto de reglas institucionales) para ser seguidos por ellos como lo correcto a realizar. Las prácticas institucionales se convierten en reglas y en el marco institucional.

El Neoinstitucionalismo histórico es la perspectiva de análisis enfocándose en la incidencia en que las instituciones tienen en los resultados y acciones públicas. Enfocando en la forma en que se despliegan a lo largo del tiempo los procesos políticos y porque están incrustados esos procesos en las instituciones, evidenciando los momentos críticos, de secuencias distintivas. Este tipo de enfoque al dar importancia a los procesos de gestación, adopción, evolución y secuencias históricas de las coaliciones de las decisiones políticas permite identificar como afectan las variables locales en el caso histórico.

En el enfoque neoinstitucionalista histórico que se utiliza se consideran las instituciones y los actores, entre los primeros existen varios órdenes institucionales, el relacionado a los grandes procesos o acontecimientos, las coaliciones, arreglos institucionales (estructuras públicas), comunidades del discurso y como actores los tomadores de decisiones, los líderes públicos con gran autoridad.

\section{RESULTADOS Y DISCUSIÓN}

\section{De las Políticas Públicas en Ecuador}

Las Políticas públicas de un país tienen consecuencias directas en el bienestar de la población, ya que las políticas públicas son instrumentos del cual se sirve el gobierno para desarrollar su acción y dar respuesta a una problemática pública. Son acciones del Estado que buscan dar respuestas a las demandas de la sociedad o segmentos de ésta.

La construcción de políticas públicas, de manera general requiere una planificación, una toma de decisiones y un proceso de análisis que en su mayoría tienen como fundamento estudios que se realizan para dar respuesta a una necesidad identificada dentro de la sociedad. En el Ecuador, desde 1978, se han desarrollado los denominados planes nacionales de desarrollo, en los diferentes periodos de Gobierno, para un total de 9 Planes de Desarrollo identificados, en cuya construcción y ejecución participan diversas instituciones y actores, los mismos que fueron realizados en el marco de las atribuciones, derechos y obligaciones consagrados en las Constituciones vigentes en sus respectivos periodos. Entendiéndose para el presente análisis que una Constitución o Carta Magna define los límites y relaciones entre los poderes del Estado; determina la organización y competencias de los poderes públicos, los fundamentos de la vida económica y social, los deberes y derechos de los ciudadanos. Las Constituciones que abarcan el periodo de 1978-2011, son: la Constitución Política de la República del Ecuador aprobada en Referéndum del 15 de enero de 1978; la aprobada en junio de 1998 y, la aprobada en Referéndum de 2008.

La historia de la construcción de agendas de política y posicionamiento de los distintos gobiernos en Ecuador permite distinguir etapas: una primera de cuestionamientos profundos y movilizaciones cuya duración y capacidad de desestabilización dependen de la demora del gobierno en anunciar las agendas, los procesos de acuerdos previos, las convocatorias y en cierto modo el apoyo del Legislativo. La segunda en la que ocurren posicionamientos de actores políticos que miran las siguientes elecciones y descubrimientos de los vacíos en las agendas o su ejecución. La tercera, basada en destacar los errores de los programas de gobierno y usualmente acompañadas de crisis económicas que no han podido ser resueltas con el ajuste y paradójicamente son amortiguadas con incrementos de último momento en el gasto público con el consiguiente desequilibrio fiscal. (Vásconez, Córdoba y Muñoz 2005) 
En este contexto, los mecanismos de traspaso como políticas públicas se dan en tres planos: el ideológico conceptual que en los años ochenta y noventa casi siempre ha provenido de influencias externas (políticas-financieras) y en pocos casos grandes movilizaciones populares; el programático en el que participan muchos sectores y actores -institucionalizados o no- en el que la discusión se centra sobre el presupuesto, más que en las prioridades de política, los criterios de eficiencia o equidad y es donde se cambian las agendas de política. Y el de la viabilidad/operatividad que tiene a su vez dos niveles: la concreción de propuestas en el imaginario colectivo a través de la participación, discusión y gestión directa de actores de la comunidad y sociedad civil; y la ejecución de acciones, programas y proyectos que pasa por la capacidad (o no) de las burocracias (Vásconez, Córdoba y Muñoz 2005).

Un estudio comparado del proceso de formulación de políticas públicas implica tener en cuenta el tipo de organización estatal y el régimen político en el cual se desenvuelve la política pública. Durante el momento de surgimiento y traspaso a la agenda política, y luego a la agenda estatal, es en donde el componente ideológico tiene intensidad máxima. El hecho de haber penetrado a la agenda estatal quiere decir que un tipo específico de discurso, o una teoría del Estado sobrepasa de lo discursivo y en donde el proceso de formulación de una política pública como una intervención estatal para resolver una situación problemática se convierte en un espacio donde lo político tiene su centralidad.

En este contexto es relevante indicar que a fines de los años noventa los gremios como las cámaras de industriales destacaron en su discurso sobre políticas de capacitación y formación profesional; y, en 1996 los sectores empresariales y de los trabajadores del país, realizaron una declaración conjunta y pública en la que definieron sobre aspectos prioritarios, entre ellos la capacitación de trabajadores. La agenda fue definida en 1996; pero, no llegó a concretarse ya que el Frente Unitario de
Trabajadores, en enero de 1997, decide suspender el diálogo, debido a diversos problemas surgidos en el gobierno de Bucaram (Chiriboga, 1997 en Milk L. 1997). En este contexto general y conforme a su mandato la Organización Internacional del Trabajo, OIT, se comprometió, a pedido del Gobierno, a apoyar el desarrollo de este proceso de diálogo social tripartito y concertación a través del proyecto sobre "Concertación Laboral" que, iniciado en 1997, culminó su trabajo en los primeros meses del 2001, y entre los logros alcanzados en materia de Capacitación y Formación Profesional se aprobó un documento de lineamientos de políticas para la creación del Sistema Nacional de Capacitación Laboral y un ante proyecto de Ley del Sistema. El documento de lineamientos fue aprobado por el Plenario (Borja, 2001).

\section{Resultados del análisis de políticas públicas de capacitación y formación profesional del periodo 1978-2011 en Ecuador}

En la Tabla 1 se esquematiza el periodo seleccionado de análisis. Se compara el periodo, los protagonistas, ideología política, la acción del periodo a nivel de gobierno, el ámbito cubierto, la orientación política de los periodos, la constitución, donde se verifica la elaboración o reforma de la constitución, características que marcaron al periodo, y las variables de alta incidencia en cada periodo.

En la Tabla 2 se anotan las instituciones que intervinieron en las distintas fases del ciclo de política pública y cuyo accionar, características, desempeño y liderazgo incidieron en el desarrollo y resultados de las acciones públicas de capacitación y formación profesional y que, por lo tanto, formaron parte del análisis integral que conllevó a la identificación de las características locales.

Tabla 1. Análisis de Políticas Públicas de Capacitación del periodo 1978-2011. Elaboración propia.

\begin{tabular}{|c|c|c|c|c|c|c|c|c|c|c|}
\hline $\begin{array}{l}\text { FASE } \\
\text { PERIODO } \\
\text { (AÑOS) }\end{array}$ & $\begin{array}{l}\text { PROTAGONISTA Y PERIODOS } \\
\text { DE GOBIERNO }\end{array}$ & IDEOLOGIA POLITICA & $\begin{array}{l}\text { PERIODO } \\
\text { POLITICO }\end{array}$ & ACCIÓN & AMBITO & $\begin{array}{l}\text { ORIENTACIÓN } \\
\text { POLÍTICA }\end{array}$ & CONSTITUCION & $\begin{array}{l}\text { CARACTERISTICA } \\
\text { DEL PERIODO }\end{array}$ & VARIABLES DE ALTA INCIDENCIA & $\begin{array}{l}\text { CAPACITACION } \\
\text { Y FORMACION } \\
\text { PROFESIONAL }\end{array}$ \\
\hline 1978-1987 & $\begin{array}{l}\text { Consejo Supremo de Gobierno } \\
\quad \text { (1976-1979); Jaime } \\
\text { Roldós(1979-1981); Oswaldo } \\
\text { Hurtado (1981-1984); León } \\
\text { Febres Cordero (1984-1988) }\end{array}$ & $\begin{array}{c}\text { Militar (1976-1979); } \\
\text { Concentración de fuerzas } \\
\text { Populares (1979- 1981); } \\
\text { Democracia Popular (1981- } \\
\text { 1984); Partido Social Cristiano } \\
\text { (1984-1988) }\end{array}$ & $\begin{array}{l}\text { Reinicio de la } \\
\text { Democracia }\end{array}$ & $\begin{array}{l}\text { 3, Planes de } \\
\text { desarrollo }\end{array}$ & $\begin{array}{l}\text { Institucional, } \\
\text { Capacitación } \\
\text { y formación } \\
\text { profesional }\end{array}$ & $\begin{array}{l}3 \text { Orientaciones } \\
\text { politicas. }\end{array}$ & $\begin{array}{l}\text { Constitución del } \\
\text { Ecuador 1967; } \\
\text { Constitución de } \\
\text { la República del } \\
\text { EEcuador, aprobada } \\
\text { en 1978, publicada } \\
\text { en 1979 }\end{array}$ & $\begin{array}{l}\text { Inicio de la } \\
\text { democracia. }\end{array}$ & $\begin{array}{l}\text { Participación de Gremios y Asociaciones; } \\
\text { Identificación política de líderes de Gremios y } \\
\text { Asociaciones; ; rientatación politica del gobierno; } \\
\text { Productividad; Percepción de corrupción en el } \\
\text { gobierno; Percepción de corrupción en instituciones } \\
\text { ejecutoras; Fortaleza de los demandantes del } \\
\text { servicio }\end{array}$ & $\begin{array}{l}\text { Creación del Servicio } \\
\text { Ecuatoriano de } \\
\text { Capacitacion y Formacion } \\
\text { Profesional, SECAP. }\end{array}$ \\
\hline 1988-1997 & \begin{tabular}{|l} 
Rodrigo Borja Cevallos (1988- \\
1992); Sixto Durán Ballén \\
(1992-1996); Abdalá Bucarám \\
(1996- 1997); Rosaliá \\
Arteaga (1997); Fabián \\
Alarcón (1997-1998)
\end{tabular} & $\begin{array}{l}\text { Izquierda Democrática } \\
\text { (1988-1992); Partido Unidad } \\
\text { Republicana (1992-1996); } \\
\text { Partido Roldosista Ecuatoriano } \\
\text { (1996-1997); Movimiento } \\
\text { Independiente para una } \\
\text { República Auténtica; Frente } \\
\text { Radical Alfarista (1997-1998) }\end{array}$ & $\begin{array}{c}\text { Periodo } \\
\text { Democrático }\end{array}$ & $\begin{array}{l}\text { 2, Planes de } \\
\text { desarrollo. } 1 \\
\text { plan de accion } \\
\text { inmediata. } 1 \text { plan } \\
\text { de transición. }\end{array}$ & Institucional, & $\begin{array}{l}4 \text { Orientaciones } \\
\text { politicas }\end{array}$ & $\begin{array}{l}\text { Sigue la misma } \\
\text { constitucion de la } \\
\text { decada anterior, con } \\
\text { varias reformas. }\end{array}$ & $\begin{array}{c}\text { Caos de } \\
\text { Gobernanza, un } \\
\text { periodo inconcluso, } \\
\text { un periodo de } \\
\text { transición no } \\
\text { concluido y } \\
\text { un periodo de } \\
\text { transición concluido }\end{array}$ & $\begin{array}{l}\text { Participación de Gremios y Asociaciones; } \\
\text { Identificación politica de líderes de Gremios y } \\
\text { Asociaciones; Orientación política del gobierno; } \\
\text { Nivel de Productividad; Percepción de corrupción } \\
\text { en el gobierrno; Percepción de corrupción } \\
\text { en instituciones ejecutoras; Fortaleza de los } \\
\text { demandantes del servicio }\end{array}$ & $\begin{array}{l}\text { Se mantiene el SECAP. } \\
\text { Inicio del diálogo social } \\
\text { tripartito el mismo que } \\
\text { es interrumpido por el } \\
\text { FUT (frente unitario de } \\
\text { trabajadores) }\end{array}$ \\
\hline 1998-2007 & $\begin{array}{l}\text { Jamil Mahuad (1998-2000); } \\
\text { Gustavo Noboa (2000-2003); } \\
\text { Lucio Gutierrez (2003-2005); } \\
\text { Alfredo Palacio(2005-2007); } \\
\text { Rafael Correa (2007-2009) }\end{array}$ & $\begin{array}{c}\text { Unión Demócrata } \\
\text { Cristiana(1998-2003); Partido } \\
\text { Sociedad Patríticica (2003-2005); } \\
\text { Alianza Páis (2007-2009) }\end{array}$ & $\begin{array}{c}\text { Periodo } \\
\text { Democrático. }\end{array}$ & $\begin{array}{l}3 \text { Planes de } \\
\text { Desarrollo }\end{array}$ & $\begin{array}{l}\text { Cambios en } \\
\text { el ambito } \\
\text { institucional y } \\
\text { fuerzas politicas }\end{array}$ & $\begin{array}{l}3 \text { Orientaciones } \\
\text { politicas }\end{array}$ & $\begin{array}{l}\text { Nueva Constitución. } \\
\text { Aprobada en } 1998 \text {. }\end{array}$ & $\begin{array}{l}\text { Caos de } \\
\text { Gobemanza. } \\
2 \text { periodos sin } \\
\text { terminar 2 } 2 \\
\text { sucesiones.Nueva } \\
\text { orientacion politica } \\
\text { y economica. }\end{array}$ & 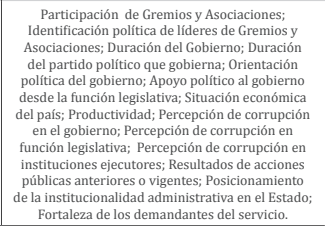 & $\begin{array}{l}\text { EI SECAP, Servicio } \\
\text { ecuatoriano de } \\
\text { capacitación y formacion } \\
\text { profesional, pierde nivel } \\
\text { deinstiticionalidad y } \\
\text { representatividad. }\end{array}$ \\
\hline 2008-2011 & $\begin{array}{l}\text { Rafael Correa (2007-2009); } \\
\text { Rafael Correa (2009-2013); }\end{array}$ & Alianza Pais & $\begin{array}{l}\text { Periodo } \\
\text { Democratico } \\
\text { de úicalínea } \\
\text { politica. }\end{array}$ & $\begin{array}{l}\text { Unico y } \\
\text { nuevo Plan } \\
\text { de edesarrollo } \\
\text { actualizado en } \\
\text { concordancia } \\
\text { a la nueva } \\
\text { constitución. }\end{array}$ & $\begin{array}{l}\text { Cambios en todos } \\
\text { los ambitos de } \\
\text { gobernanza }\end{array}$ & $\begin{array}{l}\text { Unica } \\
\text { orientación } \\
\text { politica de } \\
\text { mayoría. }\end{array}$ & $\begin{array}{l}\text { Nueva Constitución } \\
\text { aprobada en } \\
\text { 2008; Ajustes a la } \\
\text { constitución } 2011\end{array}$ & $\begin{array}{l}\text { Periodo de gobierno } \\
\text { permanente y } \\
\text { gobemanza de } \\
\text { estabilidad }\end{array}$ & 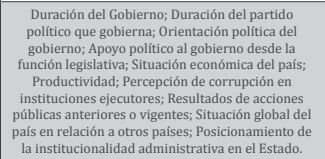 & $\begin{array}{l}\text { La institucionalidad de } \\
\text { capacitacion y formación } \\
\text { profesional se somete } \\
\text { a ajustes acordes con la } \\
\text { nueva constitución, en el } \\
\text { marco de un Sistema de } \\
\text { Capacitación y Formación } \\
\text { Profesional. }\end{array}$ \\
\hline
\end{tabular}


Tabla 2. Instituciones según su participación en el Ciclo de Políticas Públicas de Capacitación del periodo 1978-2011.

\begin{tabular}{|c|c|c|c|c|}
\hline CICLO/ FASE & FASE 1: 1978-1987 & FASE 2: 1988-1997 & FASE 3: 1998-2007 & FASE 4: 2008-2011 \\
\hline AGENDA & $\begin{array}{l}\text { Junta Nacional de Planificación (1973- } \\
\text { 1977); CONADE(1980); SECAP (1978- } \\
\text { 1999); Congreso Nacional; Asamblea } \\
\text { Nacional }\end{array}$ & CONADE(1980); SECAP (1978-1999) & $\begin{array}{l}\text { Secretaría General del Consejo de Planifica- } \\
\text { ción y Desarrollo (Oficina de Planificación } \\
\text { de Presidencia de la República) (1998); Ofi- } \\
\text { cina de Planificación ODEPLAN, Presidencia } \\
\text { de la República, 1999; Secretaría Nacional } \\
\text { de Planificación y Desarrollo, SENPLADES; } \\
\text { SECAP (1978-1999); Organizaciones Socia- } \\
\text { les, Sindicales y de la Producción; SECAP } \\
\text { (1999-2000); SECAP; CNCF }\end{array}$ & $\begin{array}{l}\text { "SENPLADES; SECAP; Secretaría Técnica } \\
\text { del CNCF; } \\
\text { Comité Interinstitucional de Capacitación } \\
\text { y Formación profesional; Organizaciones } \\
\text { Sociales, Sindicales y de la Producción } \\
\text { " }\end{array}$ \\
\hline \multicolumn{5}{|l|}{ FORMULACIÓN } \\
\hline IMPLEMENTACIÓN & $\begin{array}{l}\text { SECAP (1978-1999); INCCA (sector rural) } \\
(1979-2003)\end{array}$ & SECAP (1978-1999) & SECAP; CNCF & $\begin{array}{l}\text { SECAP; Secretaría Técnica del CNCF; Secre- } \\
\text { taría Técnica de Capacitación y Formación } \\
\text { Profesional; Comité Interinstitucional de } \\
\text { Capacitación y Formación profesional }\end{array}$ \\
\hline EVALUACIÓN & $\begin{array}{l}\text { "Junta Nacional de Planificación } \\
\text { (1973-1977); CONADE(1980); SECAP } \\
\text { (1978-1999) } \\
\text { Organizaciones Sociales, Sindicales y de la } \\
\text { Producción. }\end{array}$ & $\begin{array}{l}\text { "CONADE(1980); SECAP (1978-1999) } \\
\text { Organizaciones Sociales, Sindicales y de la } \\
\text { Producción, Organismos Internacionales } \\
"\end{array}$ & $\begin{array}{l}\text { "Secretaría General del Consejo de } \\
\text { Planificación y Desarrollo (1998); Oficina } \\
\text { de Planificación ODEPLAN, Presidencia de } \\
\text { la República, 1999; Secretaría Nacional de } \\
\text { Planificación y Desarrollo, SENPLADES; } \\
\text { SECAP; CNCF } \\
\text { Organizaciones Sociales, Sindicales y de la } \\
\text { Producción, Organismos Internacionales } \\
\text { " }\end{array}$ & $\begin{array}{l}\text { SENPLADES; Comité Interinstitucional } \\
\text { de Capacitación y Formación profesional; } \\
\text { Organizaciones Sociales, Sindicales y de la } \\
\text { Producción, Organismos Internacionales }\end{array}$ \\
\hline
\end{tabular}

NOTAS: SECAP: Servicio Ecuatoriano de Capacitación y Formación Profesional; CNCF: Consejo Nacional de Capacitación y Formación Profesional; INCCA: Instituto de Capacitación Campesina; ODEPLAN: Oficina de Planificación; CONADE: Consejo Nacional de Desarrollo; SENPLADES: Secretaria Nacional de Planificación y Desarrollo.

Elaboración propia.

\section{Identificación e incidencia de características locales que afectan la construcción de Políticas Públicas}

En los procesos de construcción de política pública, teniendo en cuenta las Instituciones como el marco en que se desarrollan las acciones o políticas públicas, y evidenciado los cambios de las instituciones de planificación, la instituciones ejecutoras o prestadoras del servicio de capacitación, así como sus interacciones con los movimientos sociales y asociaciones o gremios de la producción y laborales se identificaron veinte y ocho características que afectaron con diferente intensidad en las etapas del ciclo -entendiéndose éstas como agenda, formulación, implementación y evaluación- e indistintamente durante las fases del periodo de análisis:

1) Estructura organizacional de las instituciones de planificación y participantes; 2) (Grado de) Participación de Movimientos Sociales; 3) Recursos de Movimientos Sociales (relevancia de su aporte de recursos); 4) (Grado de) Participación de Gremios y Asociaciones; 5) Identificación política de líderes de Movimientos Sociales; 6) Identificación política de líderes de Gremios y Asociaciones; 7) Identificación política de autoridades institucionales de planificación; 8) Déficit de presupuesto; 9) Duración del Gobierno; 10) Duración del partido político que gobierna (al que pertenece el Ejecutivo que se encuentre gobernando); 11) Acontecimientos o desastres naturales; 12) (Tipo) Orientación política del gobierno; 13) Apoyo político al gobierno desde la función legislativa; 14) Situación económica del país; 15) Productividad $^{2}$; 16) Situación económica internacional; 17) Estructura de organizaciones de la sociedad civil; 18) Percepción de corrupción en el gobierno; 19) Percepción de corrupción en los movimientos sociales; 20) Percepción de corrupción en los gremios y asociaciones; 21) Percepción de corrupción en función legislativa; 22) Percepción de corrupción en instituciones ejecutores; 23) Resultados de acciones públicas anteriores o vigentes; 24) Situación global del país en relación a otros países -referida a mediciones agregadas que determinan un puesto del país respecto a otros-; 25) Posicionamiento de la institucionalidad administrativa en el Estado -se refiere a la posición, prestigio, de las instituciones ejecutoras/ rectoras de política pública en relación a la institucionalidad pública en general-; 26) Fortaleza de los demandantes del servicio -para solución del problema- (empleadores)-; 27) Fortaleza de los beneficiarios del servicio (trabajadores); 28) Tamaño de la oferta del servicio/ alternativas del servicio.

La Figura 1 muestra el resultado del análisis en referencia al nivel de incidencia de las veinte y ocho características para las distintas fases del periodo de análisis (1978-2011), estableciendo su posición en los rangos de Alto, Medio, Bajo, como un promedio de la incidencia resultante en las etapas del ciclo de política para cada fase, mismas que se anotan a continuación:

Referida a la producción en relación a los recursos invertidos, para el caso de las políticas públicas de capacitación en específico productividad laboral 


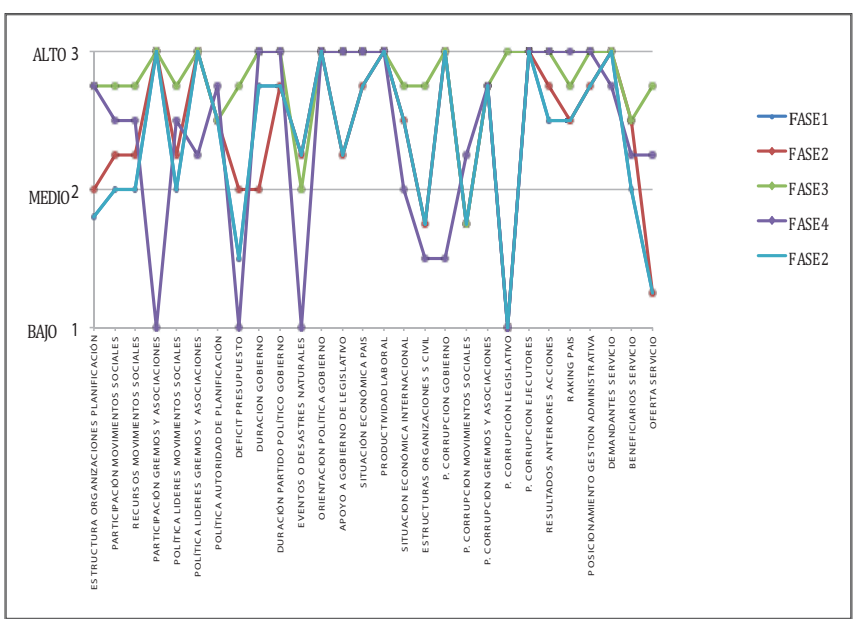

Figura 1. Niveles de Incidencia de las características locales en la construcción de Políticas Públicas.

Afectación de variables de corrupción, productividad y estructura organizacional. En las Tablas 3, 4, y 5 a continuación, se describen hechos y características de cada fase para las variables/ constructos de corrupción, productividad y estructurales organizacionales y la afectación que ha sido determinada del análisis de los procesos de construcción de política pública.

Tabla 3. Productividad y Afectación en la construcción de Políticas Públicas.

Tabla 4. Escándalos, Percepción de Corrupción y Afectación en la construcción de Políticas Públicas.

Tabla 5. Estructuras Organizacionales y Afectación en la construcción de Políticas Públicas.

\begin{tabular}{|c|c|c|}
\hline FASE & PRODUCTIVIDAD & AFECTACIÓN \\
\hline FASE 1: 1978-1987 & $\begin{array}{l}\text { Crecimiento de Producto por Persona ocupada (1950-1974): } 3,7 \text { Crecimiento de Producto por Persona ocupada por sector servi- } \\
\text { cios - } 0.3 \text {; transportes y comunicaciones } 6.9 \text {; electricidad, gas y agua } 1 \text {; minería y manufactura } 6.6 \text {; }\end{array}$ & \multirow{4}{*}{$\begin{array}{l}\text { A. Prioridad de inclusión en Agenda } \\
\text { B. Definición de sectores prioritarios en Agenda } \\
\text { C. Duración/ tipo de acciones en la formulación } \\
\text { D. Recursos para implementación } \\
\text { E. Recursos de contraparte empresas, trabajadodores } \\
\text { F. Definición de Metas/ evaluación Política }\end{array}$} \\
\hline FASE 2: 1988-1997 & $\begin{array}{l}\text { Indice de Productividad del Trabajo (OIT): año base } 1990 \text { (igual a 100). } \\
\begin{array}{lllll}\text { (1990): } 100 & (1991): 101,7 & \text { (1992): } 99,8 & \text { (1993): } 96,8 \\
(1994): 96,8 & (1995): 95,1 & (1996): 97,8 & (1997): 98\end{array}\end{array}$ & \\
\hline FASE 3: 1998-2007 & 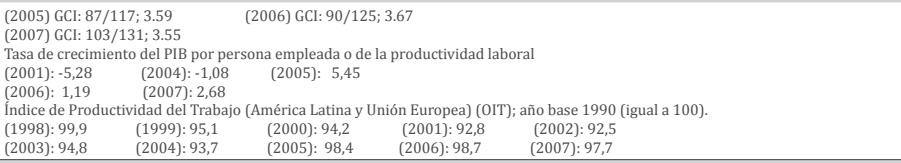 & \\
\hline FASE 4: 2008-2011 & 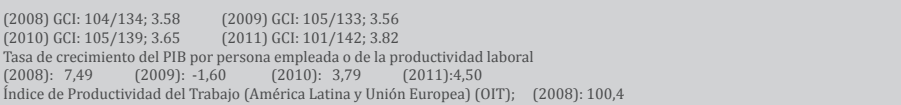 & \\
\hline
\end{tabular}

TABLA3. Fuente: (CEPAL-CEPALSTAT, 2014); (WEF,2014). Elaboración: Propia

\begin{tabular}{|c|c|c|c|c|}
\hline FASE & AÑo & ESCÁNDALOS CORRUPCIÓN & INDICADORES/ MEDICIÓN & AFECTACIÓN/ PERCEPCIÓN CORRUPCIÓN \\
\hline \multirow[b]{2}{*}{$\begin{array}{l}\text { FASE 1: } \\
\text { 1978-1987 }\end{array}$} & $1979-1984$ & $\begin{array}{l}\text { "ARROZ CON GORGOJO: Por importación de arroz de Tailandia. (1982). CASO SANTAY: } \\
\text { Expropiación permitida por el Gobierno para adjudicarla al Ministerio de Vivienda. CASO } \\
\text { MUNEEAS DE TRAPO: Sobreprecio en obsequios navideños. SUCRETIZACIÓN DE LA DEUDA } \\
\text { EXTERNA. Para favorecer al sector empresarial" }\end{array}$ & \multirow{2}{*}{$\begin{array}{l}\text { INDICE DE PERCEPCIÓN DE LA CORRUPCIÓN } \\
\text { IPC: 4,5. (1980-1985) }\end{array}$} & \multirow{6}{*}{$\begin{array}{l}\text { A. Dificultades para consenso en agenda, } \\
\text { formulación de políticas públicas. } \\
\text { B. Reformas Administrativas } \\
\text { para aumento de controles. } \\
\text { C. Burocratización de servicio } \\
\text { por aumento de controles. } \\
\text { D. Reformas Legales para aumento de } \\
\text { controles. } \\
\text { E. Deslegitimización de Reformas } \\
\text { F. Cambios de Autoridades, provocan } \\
\text { cambios en proceso de construcción de } \\
\text { políticas } \\
\text { G. Deslegitimización de Resultados }\end{array}$} \\
\hline & 1984-1987 & $\begin{array}{l}\text { "CASO FOKKER: Ministerio de Defensa implicado en un caso de sobreprecio en compra } \\
\text { de avión. (1986. ECUAHOSPITAL: Ministro de Industria sindicado por supuesto caso de } \\
\text { peculado en prestación de servicios con empresa Ecuahospital. (1987). RAN GAZIT: se } \\
\text { dictamina orden de prisiónn(1990) contra el Presidente (1986) por entrega de } 150 \text { mil } \\
\text { dólares en } 1986 \text { a su asesor de seguridad que colaboró en el combate contra la guerrilla." }\end{array}$ & & \\
\hline \multirow[b]{2}{*}{$\begin{array}{l}\text { FASE 2: } \\
\text { 1988-1997 }\end{array}$} & 1992-1996 & $\begin{array}{l}\text { FONDOS RESERVADOS: Sistema Judicial inculpó penalmente a Vicepresidente y ordenó su } \\
\text { apremio. Se exilió en Costa Rica (1995) } \\
\text { FLORES Y MIELL. Familiar del presidente acusada de utilizar influencias para obtener un } \\
\text { crédito para sus familiares(1994) }\end{array}$ & \multirow{2}{*}{$\begin{array}{l}\text { INDICE DE PERCEPCIÓN DE LA CORRUPCIÓN } \\
\text { (1988-1992) IPC: } 3,3 \\
(1993-1996) \text { IPC } 3,2 \\
(1996) \text { IPC: } 39 / 54 ; 3,19\end{array}$} & \\
\hline & 1996-1997 & $\begin{array}{l}\text { "RED PEÑARANDA. entre el Congreso Nacional y el Ministerio de Educación, para } \\
\text { construcciones escolares con contratistas escogidos por los diputados. Se crearon empresas } \\
\text { ficticias financiadas con una cuenta de la Presidencia de la República. Al descubrirse, se } \\
\text { destituýa a } 19 \text { diputadodos. La mayoriá de envolucrados huyeron (1997). } \\
\text { MOCHILA ESCOLAR: Negociado y sobreprecio para provisión de mochilas y otros } \\
\text { implementos (1997)" }\end{array}$ & & \\
\hline $\begin{array}{c}\text { FASE 3: } \\
\text { 1998-2007 }\end{array}$ & 1998-2007 & $\begin{array}{l}\text { "GASTOS RESERVADOS: Abuso de gastos reservados por parte de Ministro de Gobierno. } \\
\text { EE funcionario se fugóa aéxico (1998). } \\
\text { PIPONAZGO. Suscripción de } 2089 \text { contratos de personal innecesario en el ex Congreso } \\
\text { Nacional (1995 - 1997). S } \\
\text { ALVATAJE BANCARIO. Gobierno asume como deuda pública los compromisos que tenían las } \\
\text { instituciones financieras con las personas que depositaron sus ahorros (1999). } \\
\text { DEUDA EXTERA. Por la renegociación de la deuda Externa, s dictó orden de prisión contra } \\
\text { el Presidente (2003) " }\end{array}$ & $\begin{array}{c}\text { INDICE DE PERCEPCIÓN DE LA CORRUPCIÓN } \\
\text { (1998) IPC: } 77 / 85 ; 2.3 ; \quad(1999) \text { IPC: } 82 / 99 ; 2.4 \\
\text { (2000) IPC: } 74 / 90 ; 2.6 ; \quad(2001) \text { IP: } 79 / 91 ; 2.3 \\
\text { (2002) IPC: } 89 / 102 ; 2.2 ; \quad(2003) \text { IPC: } 113 / 133 ; 2.2 \\
\text { (2004) IPC: } 112 / 145 ; 2.4 ; \quad(2005) \text { IPC: } 117 / 158 ; 2.5 \\
\text { (2006) IPC: } 138 / 163 ; 2,3 ; \quad(2007) \text { IPC: } 150 / 179 ; 2.1 \\
\text { DEL INICE GLOBAL DE COMPETITIVIDAD } \\
\text { (2005) Comportamiento ético de las firmas } 95 / 117 ; \\
\text { Confianza en los Políticos } 116 / 117 \\
\text { (2006) Confianza en los Políticos } 121 / 125\end{array}$ & \\
\hline $\begin{array}{l}\text { FASE 4: } \\
\text { 2008-2011 }\end{array}$ & 2008-2011 & $\begin{array}{l}\text { "MINISTERIO DE DEPORTE:Investigación de corrupción por parte de un ex Ministro del } \\
\text { Deporte, por sobre precios y cobros de coimas en contratos de obras infraestructura } \\
\text { deportiva (2009). }\end{array}$ & 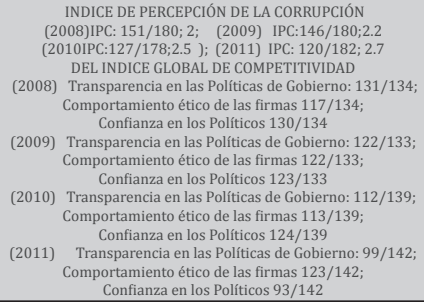 & \\
\hline
\end{tabular}

TABLA 4. Fuentes: (Función de Transparencia y Control Social. Social, 2013); (Pérez Ramirez, 2001); (CEPAL- CEPALSTAT,2014); (WEF, 2014). Elaboración: Propia. 


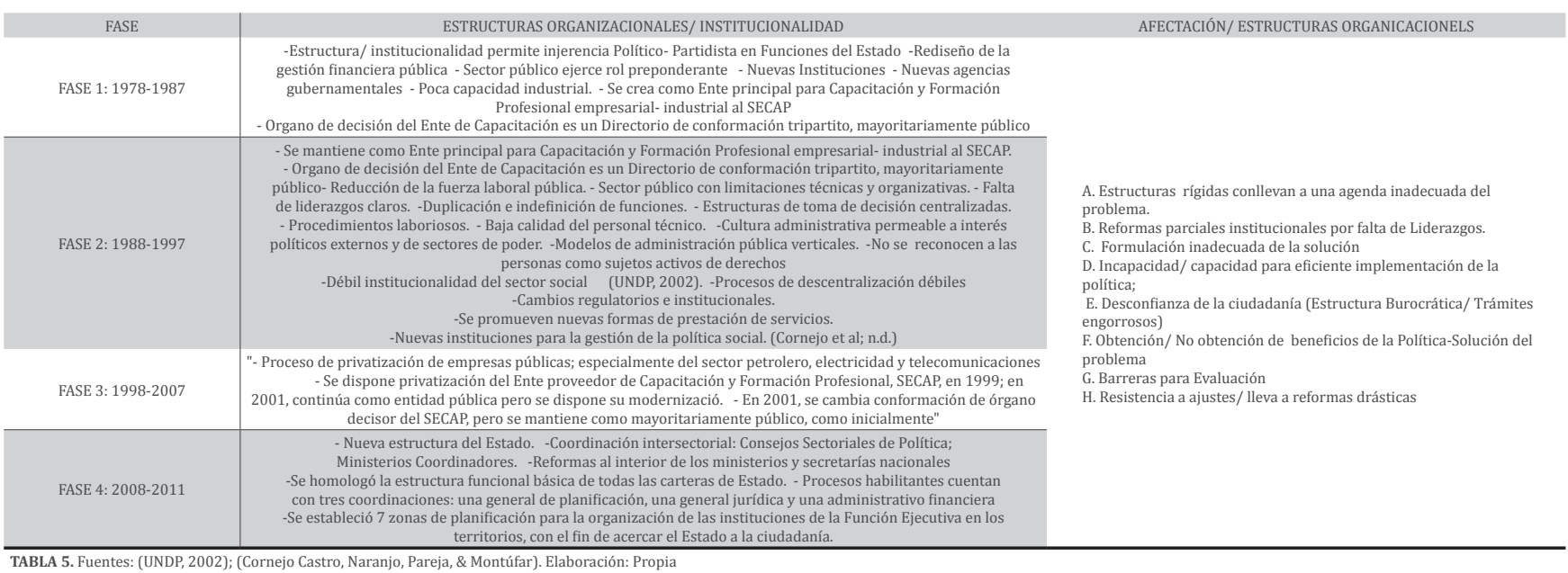

Una aproximación respecto a cómo deben considerarse las características de corrupción, productividad y estructuras organizacionales en el proceso de construcción de políticas públicas.

Estructura organizacional de las instituciones de planificación.- Se debe considerar en todo el ciclo los aspectos de: marco normativo; procesos; tipo de estructura; tamaño de estructura; tipo de estructuras territoriales; grado de concentración o desconcentración; tipodeculturaorganizacional; reformas estructurales previas a las organizaciones; relación de las causas del problema con los aspectos organizacionales de la demanda y la oferta; riesgo de que los errores organizacionales de las entidades que formulan sean replicados en el diseño de la solución; otros.

Productividad.- Se debe considerar en todo el ciclo, aspectos como: índice de productividad laboral; meta de productividad laboral; relación de la productividad con otros factores de producción; relación entre la solución al problema y la productividad laboral; prioridades de producción/ productividad; relación entre modelo de desarrollo y productividad.

Estructura de organizaciones de la sociedad civil.- Se debe considerar en todo el ciclo los aspectos de: marco normativo; procesos; tipo de estructura; tamaño de estructura; tipo de estructuras territoriales; tipo de cultura organizacional y liderazgo; relación de solución al problema con los aspectos organizacionales de la sociedad civil.

Percepción de corrupción.- Se debe considerar en todo el ciclo los aspectos de: tipo de escándalos de corrupción y relación con el problema o solución propuesta; actores individuales o institucionales en donde se percibe corrupción; precedentes de percepción de la corrupción; precedentes de reformas por percepción de corrupción; tipología de la corrupción percibida; normativa aplicada para lucha contra la corrupción.

A continuación la Figura 2 muestra la forma en que interactúan las características particulares en el ciclo del proceso de construcción de políticas públicas, la institucionalidad, actores y el contexto.

Figura 2. Interacciones de las características locales en la construcción de política pública.

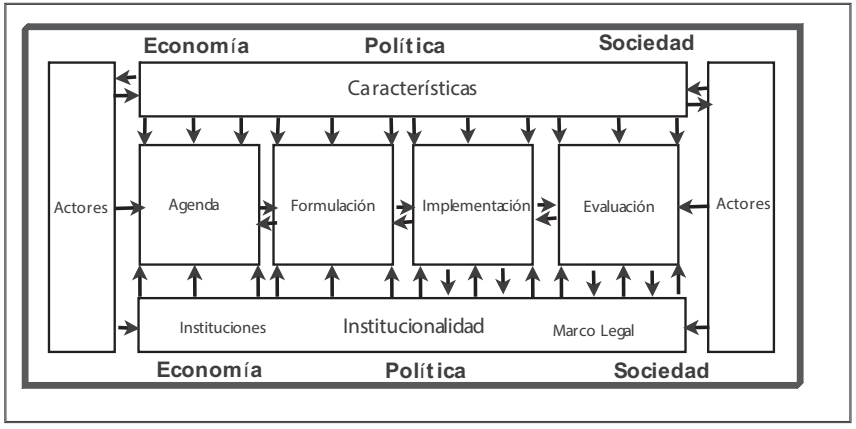

\section{CONCLUSIONES}

La corrupción, el nivel de productividad y la estructura organizacional inciden dentro del proceso de construcción de las políticas públicas en los niveles que muestran los rangos, indicadores e índices que constan en la Figura 1 y Tablas 3, 4 y 5 ; y, en los procesos de la capacitación de los trabajadores, en el estudio se verificó que:

\section{La percepción de corrupción y/o su existencia.-}

- Distorsiona los incentivos de los actores económicos hacia la búsqueda de rentas, en lugar de hacia actividades de capacitación de sus trabajadores para la mejora de la productividad 
- Dificulta el consenso durante la agenda y formulación de políticas públicas respecto a la priorización de sectores productivos y sociales a ser atendidos; beneficiarios; recursos del Estado para financiamiento; contrapartes de financiamiento; mecanismos de oferta; mecanismos de demanda.

- Genera que se identifiquen como necesarias reformas administrativas y legales frecuentes para aumentar mecanismos de control para el buen uso de recursos, incentivos, mecanismos de financiamiento, mecanismos de oferta, mecanismos de demanda, mecanismos de evaluación; durante el proceso de formulación e implementación.

- Deslegitima las reformas institucionales u organizacionales de los oferentes de capacitación, entidades de financiamiento y entidades de control y evaluación formuladas e implementadas para la solución del problema detectado.

- Disminuye el compromiso de los trabajadores, empleadores, gremios y asociaciones de la producción, y centrales sindicales durante la implementación de las acciones.

- Disminuye la responsabilidad de los centros de capacitación durante la implementación de acciones.

- Disminuye la participación de trabajadores y empleadores de determinados grupos sociales y sectores productivos durante el proceso.

- Debilita la capacidad institucional de la oferta de capacitación y formación profesional estatal y de financiamiento.

- Socava la legitimidad de las acciones de capacitación y formación profesional ejecutadas por el gobierno generando disminución de la contraparte.

- Disminuye la confianza sobre los trabajadores y empleadores que participan en el proceso generando más controles, que a la vez generan más desconfianza, generando un círculo vicioso.

- Dificulta la obtención de resultados en términos de fuerza laboral capacitada, y de la mejora de la productividad, desarrollo del país.

- Deriva hacia la no obtención de resultados por desvío de recursos.

- Socava el reconocimiento por parte de la ciudadanía, gremios y asociaciones de la producción, centrales sindicales y organizaciones sociales de los resultados obtenidos bajo la percepción y/o existencia de corrupción.

- Produce por medio de acciones formales o de facto el cambio/ destitución o salida de autoridades, principalmente de aquellas que están involucradas en la toma de decisiones.

- Genera ineficiencia e ineficacia en el proceso debido a: exagerados mecanismos de control; priorización de sectores y beneficiarios a atender basada en intereses particulares y no en las necesidades de resolver un problema público; mecanismos de financiamiento desviados para favorecer intereses particulares (60).

- Genera ineficiencia en la provisión de los servicios por desvío de recursos, por ineficiencia e ineficacia del proceso, oferta y demandas imprecisas (6P).

\section{La estructura organizacional.-}

- Permite o no la delimitación y definición efectiva de las necesidades de capacitación

- Facilita/ dificulta las reformas a los centros de capacitación y/o entidades de financiamiento.

- Confiere, entre otros factores, la capacidad/ Incapacidad para la ejecución de la capacitación (oferta)

- Facilita/ dificulta la implementación con/ sin la consecución de mejora en la productividad laboral y mejora en el desarrollo del país

- Habilita la generación de rutinas, círculos viciosos en el accionar de los servidores públicos o los agentes

- Facilita/ dificulta la tramitación con / sin problemas para la ejecución de la capacitación

- Propicia/ dificulta la confianza/ desconfianza de la ciudadanía en programas de capacitación ejecutados desde el Estado

- Facilita/Dificulta la obtención de oferta laboral capacitada

- Propicia/ dificulta las evaluaciones para el cumplimiento de la oferta laboral capacitada

- Propicia/ dificulta la obtención de datos e indicadores que permitan la evaluación de acciones e impacto o beneficios de los resultados

- Propicia/ dificulta ajustes de estructura de los centros de capacitación y/o entidades de financiamiento

\section{La productividad (el nivel).-}

- Favorece/ restringe la participación del Estado, principalmente en cuanto a aportes económicos se refiere

- Delimita las prioridades de oferta laboral capacitada y mecanismos de financiamiento

- Orienta la preparación de reformas de los centros de capacitación y/o entidades de financiamiento o cualquier manifestación de las acciones públicas de capacitación

- Delimita la duración y tipo de las acciones y mecanismos de capacitación

- Determina la especificidad en el tipo de cursos o temáticas que se requieren abordar -políticas públicas de capacitación y formación profesional-.

- Determina los recursos para la implementación y sobre ello y las posibilidades presupuestarias se definirán los recursos de contraparte, sean éstos provenientes de las mismas empresas, los trabajadores u organizaciones sociales.

- Orienta la definición de metas a alcanzar por medio de la política pública -acorde con el modelo de desarrollo-.

- Concilia las metas de las acciones públicas o política pública de capacitación y formación profesional, sin perjuicio de que la orientación política -económica sea empresarial, industrial o social y solidaria, ya que éstas se entretejen en el tejido económico - social. 
Con la definición de la forma en la que se deben considerar estas características locales en las diferentes fases del ciclo de política pública y dentro de sus etapas, se evidencia la verdadera complejidad que atraviesa la ejecución de una política pública, relevando que como indica Roth (2006), es un trabajo continuo de interpretación y de reinterpretación que depende de los actores, de su número y de la estabilidad o no del contexto de la implementación, pero también de la dinámica de las interacciones entre administración pública, actores, y los beneficiarios.

Las condiciones de producción y de evolución de las instituciones y su influencia en las dinámicas sociales, marcan en las distintas épocas su alcance en relación con la estructura productiva, los cambios en los mercados de trabajo y relaciones laborales, $y$, en los que se ha dado un valor agregado a la calificación de los trabajadores, así como la incidencia de ello en el desarrollo; definen el contexto, a su vez son parte de la reinterpretación y muestran la acción del Estado y al Estado en acción respecto a las políticas públicas de capacitación.

En condiciones de inestabilidad de contexto, multiplicidad de actores y beneficiarios, características de alta incidencia, reformas, y ajustes de institucionalidad, como en el caso de análisis, las diferentes acciones públicas merecen una continua reinterpretación y se identifica que no hacerlo o hacerlo sin considerar las características dentro de la dinámica de las interacciones entre las fases, la administración pública, actores, y los beneficiarios y, en la evolución de las instituciones, dificulta que el proceso se adapte al contexto y a su vez que las acciones se recontextualicen.

Como parte de esta recontextualización, en el caso analizado, tanto el concepto como el alcance de capacitación y formación profesional y sus sistemas han ido modificándose a lo largo del periodo, la formación ha cambiado conceptualmente, tal y como lo indica (Barreto, Ghione, Racciatti, \& Garmendia Arigón, 2003) acompañando la secuencia de los cambios en la producción y en el mundo todo del trabajo, por ello su estudio sobrellevó una visión evolutiva o histórica, desde la perspectiva de las transformaciones que ha sufrido a lo largo del tiempo.

El diseño de políticas y estrategias de formación debe considerar la interacción y participación entre las autoridades políticas y administrativas, así como con los agentes productivos y sociales; los roles de las instituciones; la diferenciación existente en las etapas de los procesos productivos; y, la incidencia de las características locales (particulares) deben estar claramente diferenciadas e identificadas para favorecer las interrelaciones, evitando desperdicio de recursos para que la evaluación que se da en los espacios de opinión pública conlleve a la satisfacción de la ciudadanía y la legitimidad de la acción del Estado.

\section{RECONOCIMIENTOS}

Lineamientos y directrices recibidos del Dr. Paulo Motta, durante el proceso de investigación.

\section{REFERENCIAS BIBLIOGRÁFICAS}

1. Alvarez, Fernando. (2002). Desarrollo Humano Reflexiones para la Superación de la Pobreza. Vol. II. Chiapas: Universidad Autónoma de Chiapas.

2. Apaza, C. (2011). Estudio comparativo sobre procesos de reforma de estructuras públicas en países seleccionados.

3. Ayala, E. (Agosto de 2008). Resumen Historia del Ecuador. Biblióteca General de Cultura 1., 3a edición, 89. (U. A. Bolívar, Ed.) Ecuador: Corporación Editora Nacional.

4. Bañón I Martinez, R. (2003). La evaluación de la acción y de las políticas públicas. Madrid, España: Díaz de Santos S.A.

5. Barreto, Ghione, H., Racciatti, O., \& Garmendia Arigón, M. (2003). El derecho de la formación profesional en Uruguay (1a edición ed.). Montevideo, Uruguay: CINTERFOR/OIT.

6. BID. (2012). Evaluación del Programa País. Ecuador 20072011. BID, Oficina de Evaluación y Supervisión, Washington.

7. BID. (2011). ¿Cómo se juega en América Latina? Instituciones políticas procesos de negociación y políticas públicas (1a edición ed.). (C. Scartascini, P. T. Spiller, E. Stein, M. Tommasi, Edits., \& M. E. S.A, Trad.) Colombia: Mayol Ediciones S.A.

8. BID. (2008). Evaluación del Programa de Ecuador: 20002006. Evaluación, BID, Oficina de Evaluación y Supervisión, VE.

9. Borja, R. (2001). El proceso de diálogo social y concertación en Ecuador 1992-2001. Oficina Internacional del Trabajo, Proyecto Concertación Laboral (ECU/97/004). PNUD. Quito: Oficina Internacional del Trabajo.

10. Bozeman, B. (. (1998). La gestión pública su situación actual. México: Fondo de Cultura Económica.

11. Bulcourf, P. A., \& Cardozo, N. D. (Octubre de 2008). ¿Por qué comparar políticas públicas? Política Comparada. arg.com .

12. Casanova, F. (2003). Formación profesional y relaciones laborales. Oficina Internacional del Trabajo, .

13. Casanova, F. (2002). Formación profesional, productividad y trabajo decente.

14. Cejas M., M. (2007). La formación profesional en América Latina. Un factor clave para el desarrollo de los países desde la Dirección Gerencial? Visión Gerencial , Año 6 (2), 207-230.

15. CEPAL. (2014). Estadísticas e Indicadores, 2000-2014. (CEPAL Comisión Económica para América Latina y el Caribe) 
Recuperado el 1 de Junio de 2014, de CEPALSTAT. Base de Datos y Publicaciones Estadísticas: http://estadisticas.cepal.org/ cepalstat/WEB_CEPALSTAT

16. Cinterfor/ OIT. (1999). Modernización de la Formación Profesional en América Latina y el Caribe. Documento de Trabajo 5, Cinterfor/ OIT.

17. CNCF. (2010). Plan Nacional de Capacitación y Formación Profesional 2010-2013. Secretaría Técnica del Consejo Nacional de Capacitación y Formación Profesional, Secretaría Técnica, Quito.

18. CNCF. (2010). Política Nacional de Capacitación y Formación laboral 2010-2013. Informe, Secretaría Técnica del Consejo Nacional de Capacitación y Formación Profesional, Secretaría Técnica.

19. Consejo Nacional de Desarrollo. (1998). Plan Estratégico de Desarrollo y Seguridad Nacional, 2025. Consejo Nacional de Desarollo . , Secretaría General de Planificación.

20. Consejo Nacional de Desarrollo. (1998). Ecuador 1999: Objetivos, Políticas y Lineamientos Estratégicos. Plan, Consejo Nacional de Desarrollo, Secretaría General de Desarrollo.

21. Consejo Nacional de Desarrollo. (1979). Plan Ecuatoriano para el Desarrollo de Recursos Humanos. Plan.

22. Consejo Nacional de Desarrollo. (1989). Plan Nacional de Desarrollo Económico y Social (1989-1992). Plan, Quito.

23. Consejo Nacional de Desarrollo. (1996). La Agenda para el Desarrollo. Plan de Acción del Gobierno Nacional 1993-1996. Plan.

24. Consejo Nacional de Desarrollo. (1985). Plan Nacional de Desarrollo (1985-1988). Plan.

25. Cornejo Castro, B., Naranjo, M., Pareja, F., \& Montúfar, M. Ecuador. Fundación Esquel, Investigación.

26. Crozier, M. (1974). El fenómeno burocrático. Buenos Aires: Amorrortu editores.

27. De la Rosa Alburquerque, A. (2002). Teoría de la organización y nuevo institucionalismo en el análisis organizacional. Administración y Organizaciones, (4), 13-44.

28. De Mattos, C. (1987). Estado, procesos de decisión y planificación en América Latina Coloquio Internacional sobre nuevas orientaciones para la planificación en economías de mercado. Revista de la CEPAL (31).

29. Echebarría, K. (15 de Noviembre de 2004). Corrupción e Indicadores de Gobernabilidad. IX Congreso Internacional del CLAD sobre la reforma del Estado y de la Administración Pública. España.

30. Ecuador. (17 de Marzo de 2011). Decreto Ejecutivo No. 680. Registro Oficial No. 406 del 17 de marzo de 2011. Ecuador.

31. Ecuador. (10 de febrero de 2011). Decreto Ejecutivo 649 . Registro Oficial 391 de 23-feb-2011. Quito, Pichincha, Ecuador.
32. Ecuador. (2010). Código Orgánico de la Producción Comercio e Inversiones.

33. Ecuador. (6 de Octubre de 2010). Ley Orgánica de Servicio Público. LOSEP. Registro Oifcial No. 294-2 Suplemento.

34. Ecuador. (9 de Enero de 2009). Decreto Ejecutivo No. 1509. Registro Oficial No. 5039 de enero de 2009.

35. Ecuador. (2008). Constitución de la República del Ecuador. Asamblea Constituyente. Montecristi.

36. Ecuador. (25 de Septiembre de 2003). Decreto Ejecutivo No. 841. Registro Oficial No. 177de 25 de septiembre de 2003. Ecuador.

37. Ecuador. (10 de Septiembre de 2001). Decreto Ejecutivo No. 1821. Registro Oficial No. 408 de 10 de septiembre de 2001. Ecuador.

38. Ecuador. (24 de Octubre de 2001). Decreto Ejecutivo No. 1976. Registro Oficial No. 439 de 24 de octubre de 2001.

39. Ecuador. (18 de Agosto de 2000). Ley para la promoción de la inversión y de la participación ciudadana. Registro Oficial No, 144 del 18 de agosto del 2000. Ecuador.

40. Ecuador. (30 de Julio de 1999). Decreto Ejecutivo No. 1106. Registro Oficial No. 245 de 30 de julio de 1999. Ecuador.

41. Ecuador. (Junio de 1998). Constitución Política de la República del Ecuador. Asamblea Nacional Constituyente.

42. Ecuador. (22 de Enero de 1979). Código Penal Ecuatoriano. Ecuador: Registro Oficial 147-Suplemento.

43. Ecuador. (19 de Octubre de 1978). Ley del SECAP No 2.928. Registro Oficial No. 694 de 19.X..1978.

44. Ecuador. (15 de Enero de 1978). Constitución Política de la República del Ecuador. Registro Oficial No. 800, 27 de marzo de 1979. Ecuador.

45. Ecuador. (25 de Mayo de 1967). Constitución de la República del Ecuador.

46. Eigen, P. (2004). Las Redes de la Corrupción. La sociedad civil contra los abusos del poder (1a edición ed.). Buenos Aires, Argentina: Planeta .

47. Farfán. (2007). El nuevo institucionalismo histórico y las políticas sociales. Polis: Investigación y Análisis Sociopolítico y Psicosocial, 3 (001), 87-124.

48. Función de Transparencia y Control Social. Social. (2013). Plan Nacional de Prevención y Lucha contra la Corrupción 20132017. Plan, Función de Transparencia y Control Social. Social, Quito.

49. Gobierno Nacional. Abdalá Bucaram. (1996). Plan de Acción Inmediata del Gobierno Nacional, 1996.

50. Guerra, F. (2001). Análsis del modelo económico y social ecuatoriano. De los años 70 s y 80 s en el marco de laglobalización. 
Tesis Maestría., FLACSO, Director. Carlos Larrea.

51. Jolias, L. (Septiembre de 2008). Inferencia causal y análisis comparado: Nuevas tendencias cualitativas . Política Comparada. arg.com, 29.

52. Junta Nacional de Planificación. (1972). Plan Integral de Transformación (1973-1976). Junta Nacional de Planificación.

53. Lahera, E. (2002). Introducción a las Políticas Públicas (1a edición ed.). Fondo de Cultura Económico.

54. Lira, L. (2006). Revalorización de la Planificación para el Desarrollo. Serie Gestión Pública (59).

55. Llamazarez, I. (1995). El análisis comparado de los fenómenos políticos. Una discusión de sus objetivos metodológicos, supuestos metateóricos y vinculaciones con los marcos teóricos presentes en las ciencias sociales conttemporáneas. Revista de Estudios Políticos Nueva Época (89), 297.

56. March, J., \& Olsen, J. (1984). The New Institutionalism: Organizational Factors in Political Life. American Political Science Review (78).

57. March, J., \& Olsen, J. (1989). Rediscovering Institutions. New York: New York Free Press.

58. March, J. G., \& Olsen, J. P. (2005). Elaborating the "New Institutionalism". Arena. Centre for european studies. University of Oslo. http://www.arena.uio.no (11).

59. Márquez, G. (2001). “Capacitación de la fuerza laboral en América Latina: ¿Qué debe hacerse?”. Primer Seminario Técnico de Consulta Regional sobre Temas Laborales, Banco Interamericano de Desarrollo, Departamento de Investigaciones, Banco Interamericano de Desarrollo, Panamá

60. Martín Mayoral, F. (2009). Estado y mercado en la historia de Ecuador Desde los años 50 hasta el gobierno de Rafael Correa. Nueva Sociedad (221).

61. MCPEC. (2010). Agenda para la Transformación Productiva 2010-2013. (Ministra Coordinadora de la Producción Empleo y Competitividad, Ed.) Ecuador.

62. Medellín, P. (2004). La política de las políticas públicas: propuesta teórica y metodológica para el estudio de las políticas públicas en países de frágil institucionalidad. Serie Políticas Sociales (93), 31.

63. Meny, I., \& Thoenig, J.-C. (1992). Las políticas públicas. Barcelona, España: Ariel.

64. Mertens, L. (1999). La Medición de la Productividad. como referente de la formación-capacitación articulada con el aprendizaje organizacional: Una propuesta metodológica. México: OIT.

65. Milk L., R. C. (1997). Movimiento obrero ecuatoriano : el desafío de la integración. Quito: Ediciones Abya-Yala. Pontificia Universidad Católica del Ecuador.
66. Moncada Sanchez, J. (1974). La evolución de la Planificación en el Ecuador. Nueva Sociedad (13), 27-45.

67. Muñoz, J. P. (15 de Septiembre de 2008). Movimientos sociales y procesos constituyentes El caso de Ecuador 2008. Recuperado el 2014, de Instituto de investigación y debate sobre la gobernanza: http://www.institut-gouvernance.org/es/ analyse/fiche-analyse-451.html

68. Nohlen, D. (2006). Ciencia Política en América Latina. Diccionario de Ciencia Política, II. (D. Nohlen, Ed.) México, México.

69. ODEPLAN. (2000). Plan de Gobierno 2000-2003 por un Nuevo País. Plan, Vicepresidencia de la República, ODEPLAN.

70. Oficina Económica y Comercial de España en Quito. (2012). Informe Económico y Comercial Ecuador. Informe, Secretaría de Estado de Turismo y Comercio.

71. Organización de las Naciones Unidas. (29 de Marzo de 1996). Convención Interamericana contra la Corrupción. Caracas, Venezuela.

72. Pasquino, G. (2004). Sistemas políticos comparados (1a edición ed.). (G. Piro, Trad.) Buenos Aires , Argentina: Bononia UNiversiy Press.

73. Paz y Miño, J. J. (noviembre de 2008). Análisis visión histórica de las constituciones de 1998 y 2008. Recuperado el 2014, de Instituto de investigación y debate sobre la gobernnanza: http:// www.institut-gouvernance.org/fr/analyse/fiche-analyse-449. html|

74. Paz y Miño, J. J. (2006). Ecuador: Una democracia inestable. HAOL. (C) Historia Actual Online 2006 (11), 89-99.

75. Pereyra, S. (2013). Política y Transparencia. La corrupción como problema público (1 a edición ed.). Buenos Aires, Argentina: Siglo veintiuno Editores S.A.

76. Perez Liñán, A. (2010). El método comparativo y el análisis de configuraciones causales. Revista Latinoamericana de Política Comparada, 3.

77. Pérez Liñán, A. (Julio de 2008). El Método Comparativo. Fundamentos y desarrollos recientes. Doumento de Trabajo No. 1. Política Comparada.Com.arg, 29.

78. Pérez Ramirez, G. (2001). Corrupción y Molinos de Viento. Obtenido de Revista Probidad: http://www.revistaprobidad. info/

79. Pérez, E. (s.f.). La administración pública ecuatoriana en el siglo $\mathrm{xx} .25$

80. Peters, G. (1999). La Política de la Burocracia. México, México: Fondo de CUltura Económica.

81. Posthuma, A. C. (2002). Transformaciones recientes en la formación profesional y diálogo social en América Latina. Diálogo social, Formación Profesional e Institucionalidad. 
82. Powel, W. W., \& Dimaggio, P. (. (1999). El nuevo institucionalismo en el análisis organizacional (1a. Edición ed.). (S. N. Gobierno, Ed.) México D.F., México: Fondo de Cultura Económica.

83. Pronko, M. (2005). Recomendación 195 de OIT. Cuestiones históricas y actuales de la formación profesional. Montevideo, Uruguay: CINTERFOR. OIT.

84. Ramió, C. (1999). Teoría de la Organización y Administración Pública. Barcelona, España: Tecnos.

85. Reyes, O., \& Hernández, A. (2008). El estudio de caso en el contexto de la crisis de la modernidad. (32), 70-89.

86. Ritzer, G. (1993). Teoría Sociológica Contemporánea. México, México: Mc Graw Hill.

87. Roth Deubel, A.-N. (2006). Políticas Públicas. Formulación, implementación y evaluación (Quinta edición ed.). Bogotá, Colombia: Ediciones Aurora.

88. Sartori, G. Comparación y método comparado. En S. Giovanni, \& M. Leonardo, La comparación en las Ciencias Sociales (págs. 29-50). Madrid, España: Alianza Editorial S.A.

89. Selznick, P. (1996). Institutionalism "Old" and "New. Administrative Science Quarterly, 41, 270-277.

90. SENPLADES. (2012). Folleto informativo . Proceso de desconcentración del Ejecutivo en los niveles administrativos de planificación. 1a, 20. Quito, Ecuador.

91. SENPLADES. (11 de Agosto de 2011). SENPLADES. Obtenido de Seguimiento y Evaluación: http://senplades.gov.ec

92. SENPLADES. (2009). Plan Nacional para el Buen Vivir 20092013. Plan, SENPLADES.

93. SENPLADES. (2007). Plan Nacional de Desarrollo 2007-2011. Agenda, SENPLADES.

94. Subirats Joan, K. P. (2008). Análisis y gestión de políticas públicas (1a. edición ed.). Barcelona, España: Ariel, S. A. .

95. Szelubski, J. (2009). La corrupción embate de la democracia latinoamericana. Un enfoque multidisciplinario. Las Tesis de Belgrano: (50) . Buenos Aires, Argentina.

96. Thoenig, J.-C. (2000). New Institutionalism and organizational theory: A review Article. Reviews, 455-460.

97. UNDP. (2002). Evaluación Común de País. Visión de las Naciones Unidas sobre la situación del Ecuador. Evaluación, UNDP.

98. Vásconez, A., Córdoba, R., \& Muñoz, P. (2005). La construcción de las políticas sociales en Ecuador durante los años ochenta y noventa: sentidos, contextos y resultados. Serie Políticas Sociales (105), 83.

99. Verdesoto, L. (1999). Las Agendas del Desarrollo del Ecuador de los "90". Centro de Planificación y Estudios Sociales. CEPLAES.
Quito: Ediciones ABYA AYALA.

100. Weber, M. (2005). ¿Qué es la burocracia? (Segunda Reimpresión ed.). México D.F., México: Ediciones Coyoacán.

101. Weber, M. (2004). El Político y el científico (Sexta Reimpresión ed.). Madrid, España: Alianza Editorial.

102. World Economic Forum. (2014). Reports. The Global Competitiveness Report 2014 - 2015. Recuperado el 31 de Agosto de 2014, de Sitio Web de World Economic Forum: http://www.weforum.org/reports/global-competitivenessreport-2014-2015

103. Yin, R. K. (1994). Investigacion sobre Estudio de Casos Diseño y Métodos . Applied Social Research Methods Series, 5, 2 a. New Delhi, London: SAGE publications. 